\title{
Evaluation of a Novel Water Treatment Residual Nanoparticles as a Sorbent for Arsenic Removal
}

\author{
Elsayed Elkhatib, Ahmed Mahdy, Fatma Sherif, and Hala Hamadeen \\ Department of Soil and Water Sciences, Alexandria University, Alexandria 21545, Egypt \\ Correspondence should be addressed to Elsayed Elkhatib; selkhatib1@yahoo.com
}

Received 24 August 2015; Revised 20 September 2015; Accepted 21 September 2015

Academic Editor: Sesha Srinivasan

Copyright (C) 2015 Elsayed Elkhatib et al. This is an open access article distributed under the Creative Commons Attribution License, which permits unrestricted use, distribution, and reproduction in any medium, provided the original work is properly cited.

A novel sorbent, water treatment residual nanoparticles (nWTR), was synthesized and used to remove As(V) from water solutions. The kinetics and equilibrium of $\mathrm{As}(\mathrm{V})$ adsorption by $\mathrm{nWTR}$ were evaluated. The kinetic data for $\mathrm{nWTR}$ at 3 different $\mathrm{pH}$ values indicate that $\mathrm{As}(\mathrm{V})$ sorption is biphasic, is favored at low $\mathrm{pH}$ values, and followed the power function and first-order kinetics models fit. The results of the batch adsorption study showed that nWTR was effective in As(V) removal and its removal capability was 16 times higher than that of bulk WTR. Fourier transmission infrared (FTIR), SEM-EDX spectra, and As fractionation results indicate the crucial role of surface hydroxyl groups in As retention onto nWTR and the high capability of nWTR to immobilize As(V). The stability of As-nWTR surface complexes is suggested as less than $2 \%$ of adsorbed As(V) was released from nWTR after 4 consecutive desorption cycles.

\section{Introduction}

Arsenic (As) is listed in the US-EPA priority pollutant list with known adverse effects on humans and environment health. Land application of As based pesticides and biosolids, disposal of industrial wastes, and mining activities are the major sources of anthropogenic arsenic in soil and water ecosystems. The strong ability of As to accumulate in food chains can lead to living organisms' toxicity and pose greater risks to our health and the environment $[1,2]$.

Several remediation technologies are available to reduce As concentrations in soil and water systems high in As [3-6]. However, many of these technologies have shown limitations in removing the toxic contaminants from contaminated water to safe levels and they are costly, laborious, and time-consuming $[7,8]$. Research on the development of inexpensive and green remediation techniques remains a challenge.

Water treatment residuals (WTRs), waste products from drinking water treatment facilities, have been gaining increased attention recently as an ecofriendly and low cost adsorbent. Because of their amorphous nature, WTRs have shown strong affinity for $\mathrm{P}, \mathrm{As}, \mathrm{Ni}, \mathrm{Cu}$, and $\mathrm{Pb}$ [9-13].
Moreover, conclusive prior studies have demonstrated that the smaller fraction of WTR greatly influences its active surface area and leads to increase its adsorption capacity [12-14]. Recently, Elkhatib et al. [13] developed a method to produce nanoparticles sorbent from water treatment residues using precision milling. They reported that the $\mathrm{P}$ sorption capacity of the produced nanoparticles was 30 times higher than the $\mathrm{P}$ sorption capacity of bulk water treatment residuals. The comparatively greater adsorption capacity and stability of water treatment residual nanoparticles (nWTR) suggest their use as a very promising and practical solution to remediate various environmental contaminants. For the best of our knowledge, information is not available in the literature on the potential use of nanoscale WTRs in removal of arsenic from aqueous media. The objectives of this study were to (1) determine arsenic adsorption capacity of water treatment residual nanoparticles and to investigate the pertinent adsorption mechanism and (2) study the effects of operational parameters including adsorbent dosages, solution $\mathrm{pH}$, and coexisting cations on the removal of As by nWTR. Such a study is important for practical guidance and for gaining future acceptance in utilizing nWTR as a remediation agent for waste water and freshwater. 


\section{Experimental}

2.1. Synthesis and Characterization of $n W T R$. The bulk WTR (mWTR) was obtained from the drinking water treatment plant in Kafr El-Dawar, El Beheira, Egypt. The plant uses aluminum sulfate for flocculation. The WTR samples were collected, transported to the laboratory, and air-dried. Subsamples were ground and passed through two different sieves having $2 \mathrm{~mm}$ (mWTR) and $51 \mu \mathrm{m}$ ( $\mu \mathrm{WTR})$ of pore diameters. Synthesis of nanoscale WTR was achieved by milling subsamples of $\mu \mathrm{WTR}(<51 \mu \mathrm{m})$ using Fritsch Planetary Mono Mill [13]. The characteristics and element contents of nWTR, mWTR, and $\mu$ WTR were investigated using transmission electron microscopy (TEM), X-ray diffraction (XRD), scanning electron microscopy (SEM) with energy dispersive $\mathrm{X}$ ray (INCAx-Sight model 6587, Oxford Instruments, UK), and autosorb iQ surface area analyzer (Quantachrome, USA) and the results have been reported elsewhere [15].

2.2. Adsorption Kinetics. Adsorption kinetic experiments were carried out at room temperature $\left(23^{\circ} \mathrm{C}\right)$ using the batch technique. A dose of nWTR (100 mg) and $20 \mathrm{~mL}$ of As(V) solutions with the initial concentration of $350 \mathrm{mg} / \mathrm{L}$ were placed in $50 \mathrm{~mL}$ centrifuge tubes and shaken using an endover-end shaker for different time intervals (5 min-24h) at 3 different $\mathrm{pH}$ levels ( $\mathrm{pH} 5,7$, and 9). The $\mathrm{pH}$ of each suspension was kept constant by adding $\mathrm{HCl}$ or $\mathrm{NaOH}$ using the automatic titrator. The As-nWTR suspensions were centrifuged at $4000 \mathrm{rpm}$ for $10 \mathrm{~min}$ and the supernatant solutions were filtered through a membrane filter $(0.45 \mu \mathrm{m}$; Millipore Corp.). The concentrations of As in the supernatant solutions were analyzed by the atomic absorption spectrometry method (AAS, Perkin Elmer Optima 2000 DV). Arsenic(V) solutions were prepared from stock standard $\mathrm{Na}_{2} \mathrm{HAsO}_{4}$ solution $\left(1000 \mathrm{mgL}^{-1}\right)$. The kinetics of As adsorption on the nWTR samples was investigated by fitting the sorption data to power function, parabolic diffusion, first-order, and Elovich kinetic models.

2.3. Adsorption Isotherms. Arsenic(V) sorption equilibrium studies were performed on three sizes of WTR ( $2 \mathrm{~mm}$ (bulk WTR), <51 micron ( $\mu$ WTR), and $<100 \mathrm{~nm}(\mathrm{nWTR}))$ at As(V) concentrations ranging from 0 to $160 \mathrm{mg} / \mathrm{L}$. The adsorption studies were conducted at normal $\mathrm{pH}$ (7.2) using $0.01 \mathrm{M}$ $\mathrm{K}_{2} \mathrm{SO}_{4}$ as background electrolyte. The WTR-As mixtures were equilibrated on an end-over-end shaker for $24 \mathrm{~h}$ (predetermined equilibrium adsorption time) and centrifuged at $4000 \mathrm{rpm}$ for $10 \mathrm{~min}$ and the supernatant solutions were filtered through a membrane filter $(0.45 \mu \mathrm{m}$; Millipore Corp.). All experiments were performed in triplicate, and solutions were analyzed for As by AAS. The sorption data were then fitted to seven different isotherm models and the best fit model was used to calculate the maximum sorption capacity [15]. The solid nWTR material used in these sorption experiments was recovered and examined for sorbed As via scanning electron microscopy (SEM), equipped with an X-ray energy dispersive spectrometer (SEM-XED).
The effect of $\mathrm{pH}$ on $\mathrm{As}(\mathrm{V})$ adsorption by nanoscale WTR was studied in the $\mathrm{pH}$ range of 3-11 at room temperature. A dose of nWTR (0.1 g) and $20 \mathrm{~mL}$ of As(V) solutions with the initial concentration of $150 \mathrm{mg} / \mathrm{L}$ were placed in $50 \mathrm{~mL}$ centrifuge tubes and shaken using an end-over-end shaker for $15 \mathrm{~min}$ at different $\mathrm{pH}$ levels (3-11). The $\mathrm{pH}$ of each suspension was kept constant by adding $\mathrm{HCl}$ or $\mathrm{NaOH}$ using the automatic titrator. The As-nWTR suspensions were centrifuged at $4000 \mathrm{rpm}$ for $10 \mathrm{~min}$ and the supernatant solutions were filtered through $0.45 \mu \mathrm{m}$ Millipore membrane filters. The concentrations of As in the supernatant solutions were analyzed by AAS.

For the determination of optimal dosage of nWTR, three masses $(0.02,0.05$, and $0.10 \mathrm{~g})$ were shaken with $10 \mathrm{~mL}$ each of different $\mathrm{As}(\mathrm{V})$ concentrations $\left(0-500 \mathrm{mg} \mathrm{L}^{-1}\right)$ contained in $50 \mathrm{~mL}$ centrifuge tubes for $24 \mathrm{~h}$ using end-over-end shaker. The suspensions were then centrifuged at $4000 \mathrm{rpm}$ for $10 \mathrm{~min}$ and the supernatant solutions were filtered.

The effect of initial As(V) concentration on the extent of adsorption was investigated at the initial As concentrations of $5,20,40,80$, and $160 \mathrm{mg} / \mathrm{L}$. The experiments were performed by adding $0.10 \mathrm{~g}$ of nWTR sample to $20 \mathrm{~mL}$ of As solutions. The mixtures were shaken on the orbital shaker for $24 \mathrm{~h}$ and then removed for centrifugation. After centrifugation, the supernatant solutions were transferred into clean tubes and kept under refrigeration $\left(-4^{\circ} \mathrm{C}\right)$ until analysis. To evaluate the effect of coexisting ions on As adsorption by nWTR, similar set of experiments were performed in the presence of two competing cations ( $\mathrm{Hg}$ and $\mathrm{Cr}$ ) at concentrations equal to $\mathrm{As}(\mathrm{V})$ concentration. All experiments were performed in triplicate, and solutions were analyzed for As by AAS.

\section{Results and Discussion}

3.1. Characterization of $n W T R$. The SEM analysis of nWTR samples showed that the WTR nanoparticles are spherical with sizes in the range of 45 to $96 \mathrm{~nm}$ and the EDX analysis revealed the prominence of iron, silicon, calcium, and aluminum in nWTR (Figure 1(a)). The X-ray diffraction analysis (Figure 2) confirmed EDX results and ascertained amorphous iron, aluminum (hydr)oxides, and silicon oxide dominating all nWTR, with no apparent crystalline iron-Al (hydr)oxides. The SEM images of nWTR before and after saturation with As ions are shown in Figures 1(a) and 1(b). The figures showed a coating layer of adsorbed arsenic on the surface of the nWTR after arsenic adsorption. The SEM-EDX analysis spectrum (Figure 1(b)) ascertained the appearance of As peak (7.52\%) amongst the elements detected in Assaturated nWTR. An important feature of the EDX results is a clear reduction in the intensity of the iron peak in the As-saturated nWTR which suggests arsenate exchange with $\mathrm{FeOH}$ in the aqueous system.

3.2. Arsenic Adsorption versus Time. The effects of contact time (15 min to $24 \mathrm{~h}$ ) on adsorption of As(V) by nWTR at $\mathrm{pH}$ values 5, 7, and 9 were evaluated, and the results are presented in Figure 3. Adsorption of As(V) by the nWTR was biphasic, consisting of an immediate sorption phase followed 

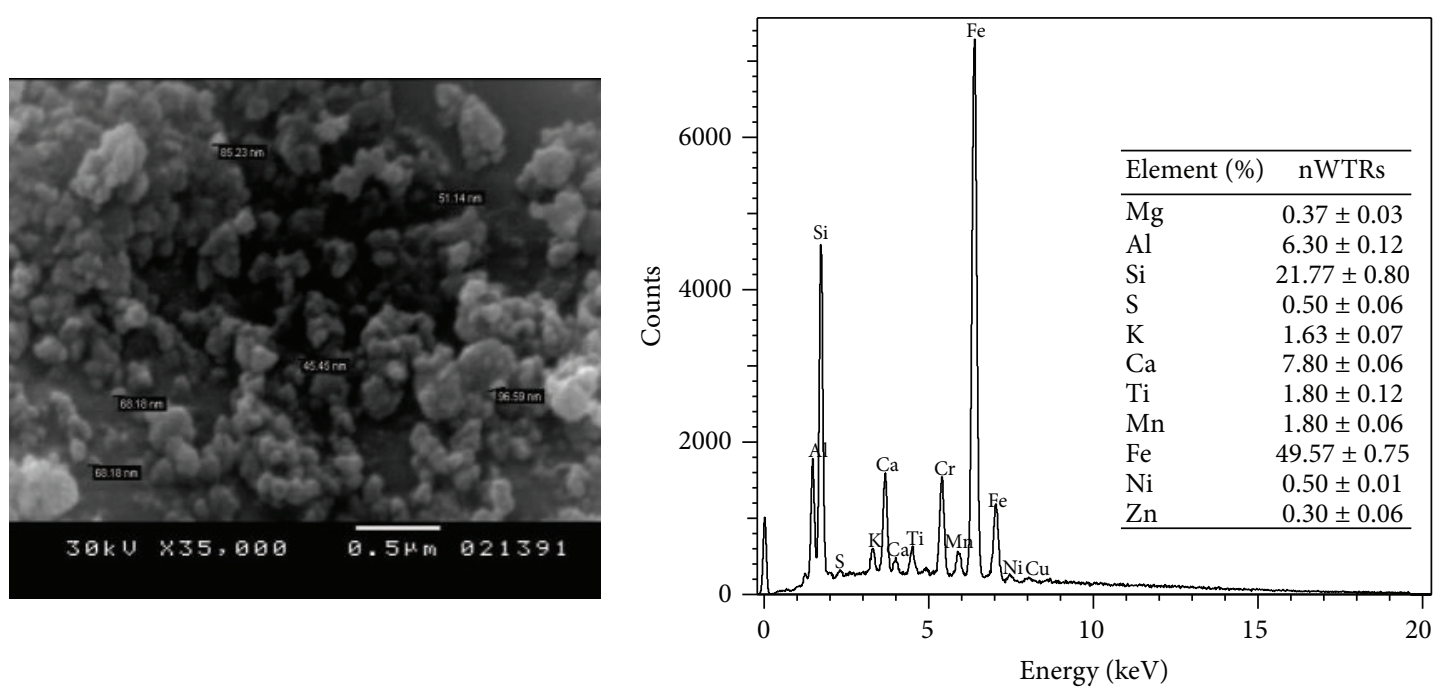

(a)
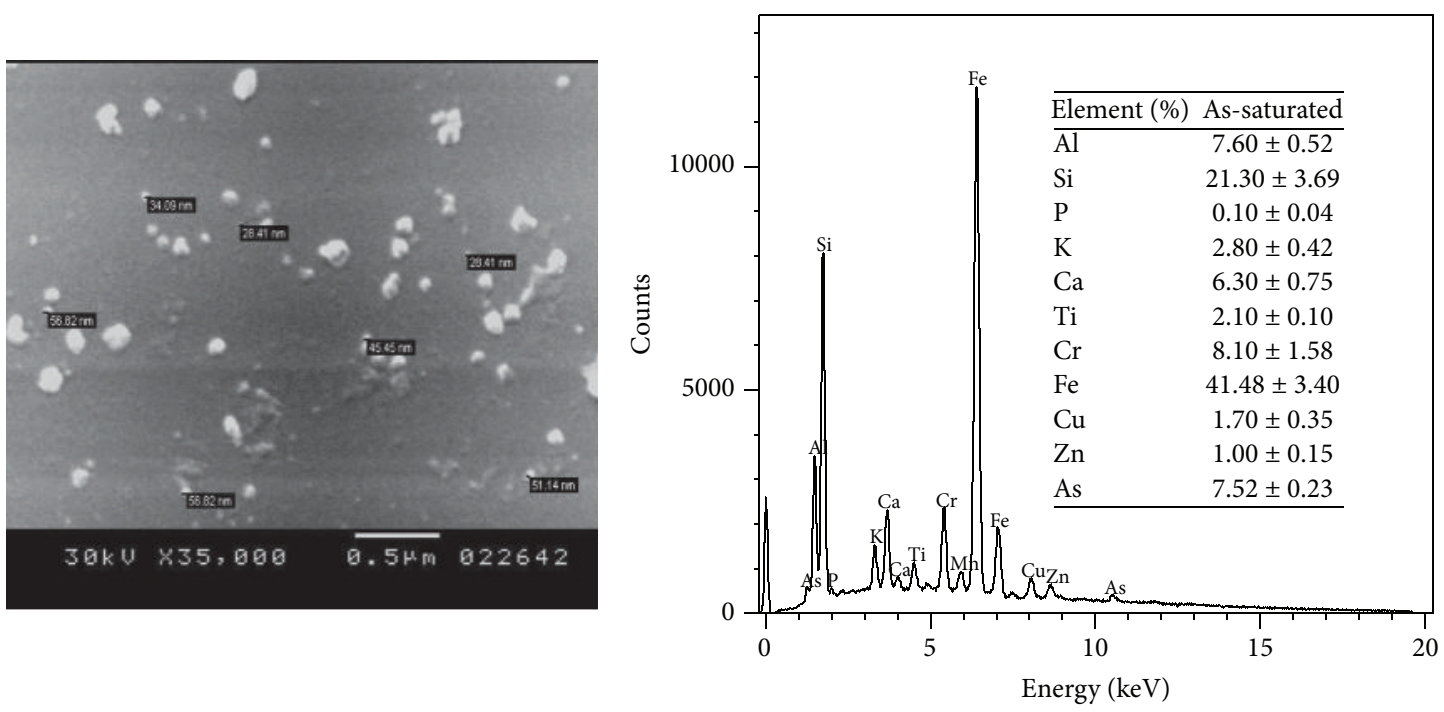

(b)

FIGURE 1: Scanning electron microscopy (SEM) image and energy dispersive X-ray (EDX) spectrum of (a) nWTR and (b) the As-saturated nWTR. The figures showed that a coating layer of adsorbed arsenic is formed on the surface of the nWTR after arsenic adsorption.

by a much slower sorption phase. The rapid adsorption of As $(\mathrm{V})$ by nWTR could be due to the availability of active adsorption sites. Figure 3 also presents that $\mathrm{As}(\mathrm{V})$ adsorption on nWTR decreased as $\mathrm{pH}$ increased from 5 to 9 . This could be attributed to the increase of negative-charge sites on the nWTR surface at high $\mathrm{pH}$ values. At $\mathrm{pH}>9, \mathrm{HAsO}_{4}{ }^{2-}$ is the dominant $\mathrm{As}(\mathrm{V})$ species that may compete with negative site of the nWTR surface to reduce the adsorption capability due to electrostatic repulsion [16]. Approximately $89 \%$ of As was adsorbed by nWTR within the first $15 \mathrm{~min}$ and slowly preceded to $100 \%$ sorption by the end of the $24 \mathrm{~h}$ period. Therefore, using nWTR for $\mathrm{As}(\mathrm{V})$ removal is practical and highly efficient. Similar biphasic As kinetic sorption data were obtained for the Fe-WTR [17].

The kinetically driven $\mathrm{As}(\mathrm{V})$ adsorption data at three $\mathrm{pH}$ solution values $(5,7$, and 9) were fitted to first-order, Elovich, intraparticle diffusion, and power function models [18]. The power function model best described $\mathrm{As}(\mathrm{V})$ adsorption on nWTR as $R^{2}$ values of the model were quite high (significant at $p<0.01$ ) and SE values were the lowest (Table 1 and Figure 4). The adsorption kinetics of arsenate on Fe-Si binary oxide adsorbent was also reported to follow power function model [19]. The first-order kinetics model fits the adsorption experimental data satisfactorily as evidenced by the $R^{2}$ and SE values. The much higher SE values of parabolic and Elovich models than those of power function and first-order models indicate that the predictive capability of these models to describe sorption data is not satisfactory (Table 1). Power function model parameters of As(V) sorption by nWTR as affected by solution $\mathrm{pH}$ are given in Table 1 . The decrease in the adsorption rate $\left(k_{a}\right)$ of the power function model from $6.22 \times 10^{4}$ to $1.99 \times 10^{4} \mathrm{~min}^{-1}$ with the increase in the system 


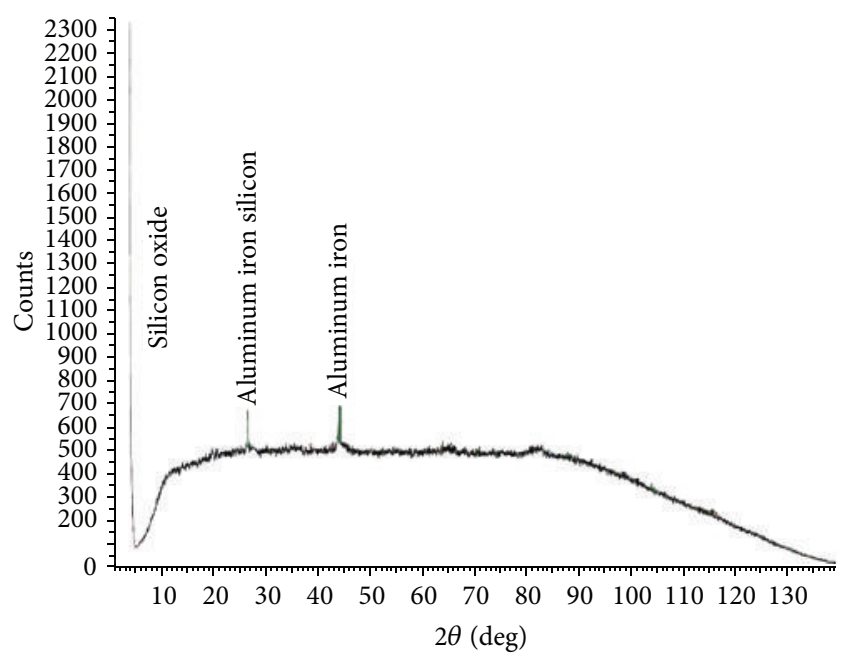

FIGURE 2: The X-ray diffraction (XRD) analyses of WTR nanoparticles. The XRD results ascertained amorphous iron, aluminum (hydr)oxides, and silicon oxide dominating all nWTR, with no apparent crystalline iron-Al (hydr)oxides.

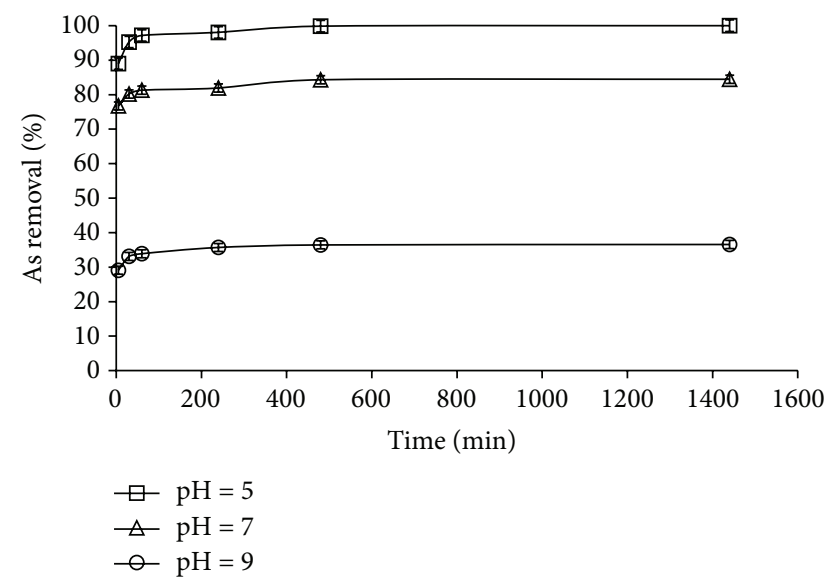

FIgURE 3: Effect of contact time on the removal of As(V) by nWTR at three different $\mathrm{pH}$ values. Notice that approximately $89 \%$ of As was adsorbed by nWTR within the first $15 \mathrm{~min}$.

$\mathrm{pH}$ from 5 to 9 indicates that $\mathrm{As}(\mathrm{V})$ sorption is favored at low $\mathrm{pH}$ values.

3.3. Equilibrium Adsorption Studies. Equilibrium studies were performed to determine the maximum sorption capacity of WTR nanoparticles in comparison to mWTR and $\mu \mathrm{WTR}$. The adsorption isotherm data for the three different particle sizes of WTR was fitted to seven isotherm models (Freundlich, Langmuir, Elovich, Temkin, Kiselev, FowlerGuggenheim, and Hill-de Boer) [15, 20, 21] for reliable prediction of adsorption parameters including maximum sorption capacity. The models tested and associated parameters are presented in Table 2. The coefficients of determination $\left(R^{2}\right)$ for all of the models tested were quite high. However, the SE values of Freundlich, Fowler-Guggenheim, Hill-de Boer, Elovich, and Kiselev models were much higher than the SE

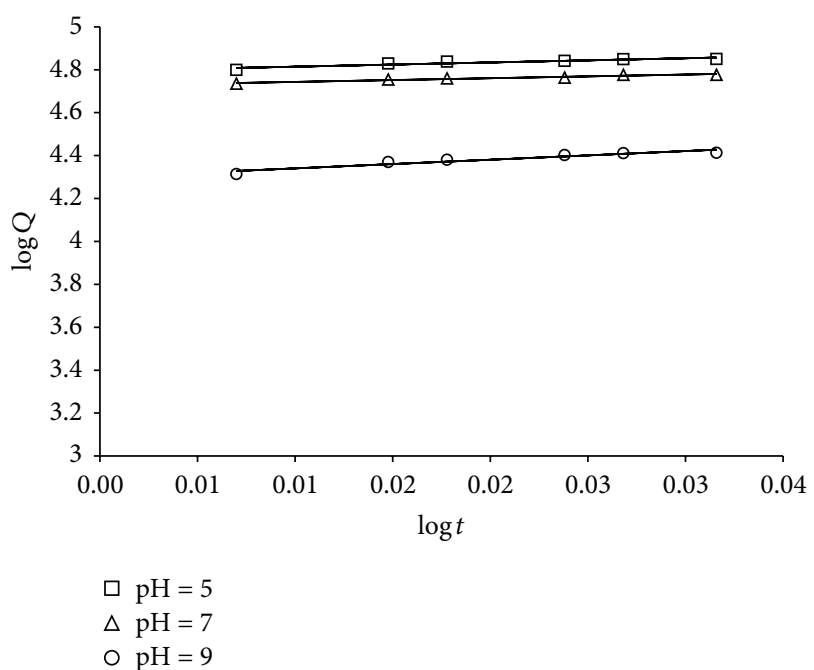

FIGURe 4: Power function kinetics model for $\mathrm{As}(\mathrm{V})$ adsorbed onto nWTR at three different $\mathrm{pH}$ Values.

values of Langmuir and Temkin models. This indicates the low predictive capability of Freundlich, Fowler-Guggenheim, Elovich, and Kiselev models to describe sorption date (Table 2). Therefore, Freundlich, Fowler-Guggenheim, Hillde Boer, Elovich, and Kiselev models were not analyzed further.

Langmuir Isotherm Model. $R^{2}$ and the SE values of Langmuir models for all sorbent-As systems are presented in Table 2. Arsenic sorption data conformed to the Langmuir model over the entire concentration range for all three particle sizes of WTR studied as evidenced by the high $R^{2}$ values $(p>$ 0.001 ) and the low SE values of Langmuir model (Figure 5). The conformity of adsorption data to Langmuir model suggested the homogeneous and monolayer mode of adsorption. The Langmuir $K_{L}$, a coefficient attributed to the affinity between the sorbent and As, values for mWTR, $\mu \mathrm{WTR}$, and nWTR were $1.8,144.4$, and $250\left(\mathrm{mg} \mathrm{g}^{-1}\right)$, respectively. It is clear that As sorption affinities expressed by Langmuir $K_{L}$ values follow the sequence nWTR $>\mu \mathrm{WTR}>\mathrm{nWTR}$. The maximum adsorption capacity $\left(q_{\max }\right)$ for mWTR, $\mu \mathrm{WTR}$, and nWTR was 3.33, 5.0, and $50 \mathrm{mg} \mathrm{As} \mathrm{g}^{-1}$, respectively (Table 2). It is interesting to note that the $q_{\max }$ of WTR nanoparticles is 16 times higher than $q_{\max }$ of Bulk WTR. This could be due to the smaller size and higher surface area $\left(129 \mathrm{~m}^{2} \mathrm{~g}^{-1}\right)$ of WTR nanoparticles compared to bulk WTR $\left(53.1 \mathrm{~m}^{2} \mathrm{~g}^{-1}\right)$. Large surface area leads to high adsorption capacity and surface reactivity [20].

Temkin Isotherm Model. The data of As(V) sorption onto the three particle sizes of WTR were analyzed according to the linear form of the Temkin isotherm and the linear plots are shown in Figure $5 . R^{2}$ and SE values of Temkin models indicate that Temkin model satisfactory fits to the As sorption data for all the three WTR particle sizes studied (Table 2). However, Langmuir model showed a better fit to adsorption data than Temkin model. The Temkin 
TABLE 1: Kinetics model parameters and determination coefficients and standard error of estimate for arsenic adsorption by nWTR at $3 \mathrm{pH}$ values.

\begin{tabular}{|c|c|c|c|c|}
\hline Models & Parameter & pH 5 & pH 7 & pH 9 \\
\hline \multirow{4}{*}{$\begin{array}{l}\text { Elovich } \\
q_{t}=(1 / \beta) \ln (\alpha \beta)+(1 / \beta) \ln t\end{array}$} & $\alpha \mathrm{mgg}^{-1} \min ^{-1}$ & $2.11 \times 10^{23}$ & $7.32 \times 10^{26}$ & $1.25 \times 10^{12}$ \\
\hline & $\beta \mathrm{mg} \mathrm{g}^{-1}$ & $7.49 \times 10^{-4}$ & $1.03 \times 10^{-3}$ & $1.06 \times 10^{-3}$ \\
\hline & $R^{2}$ & 0.89 & 0.94 & 0.92 \\
\hline & SE & 1100 & 536 & 619 \\
\hline \multirow{4}{*}{$\begin{array}{l}\text { First-order } \\
\text { In }\left(q_{o}-q\right)=a-k_{a} t\end{array}$} & $k_{a} \min ^{-1}$ & -0.008 & -0.007 & -0.008 \\
\hline & $a \mu \mathrm{gg}^{-1}$ & 8.59 & 8.50 & 8.24 \\
\hline & $R^{2}$ & 0.93 & 0.91 & 0.98 \\
\hline & SE & 0.32 & 0.25 & 0.28 \\
\hline \multirow{4}{*}{$\begin{array}{l}\text { Parabolic diffusion } \\
q=a+k_{d} t^{1 / 2}\end{array}$} & $k_{d} \mu \mathrm{gg}^{-1} \min ^{-1 / 2}$ & 166.52 & 130.67 & 119.15 \\
\hline & $a \mu \mathrm{gg}^{-1}$ & 6580 & 5570 & 2240 \\
\hline & $R^{2}$ & 0.58 & 0.72 & 0.62 \\
\hline & SE & 2120 & 1200 & 1380 \\
\hline \multirow{4}{*}{$\begin{array}{l}\text { Power function } \\
q=k_{a} C_{o} t^{1 / m}\end{array}$} & $k_{a} \min ^{-1}$ & $6.22 \times 10^{4}$ & $5.33 \times 10^{4}$ & $1.99 \times 10^{4}$ \\
\hline & $1 / m$ & 0.020 & 0.017 & 0.040 \\
\hline & $R^{2}$ & 0.88 & 0.94 & 0.91 \\
\hline & SE & 0.007 & 0.004 & 0.013 \\
\hline
\end{tabular}

$q$ or $q_{t}$ is As adsorbed $\left(\mathrm{mg} \mathrm{kg}^{-1}\right)$ at time $t, q_{o}$ is As adsorbed $\left(\mathrm{mg} \mathrm{kg}^{-1}\right)$ at equilibrium, $k_{a}$ is apparent sorption rate coefficient, $\alpha$ is the initial adsorption rate $\left(\mathrm{mg} \mathrm{g}^{-1} \min ^{-1}\right), \beta$ is a constant related to the extent of surface coverage $\left(\mathrm{mg} \mathrm{g}^{-1}\right), a$ is a constant; $k_{d}$ is apparent diffusion rate coefficient, $q$ is adsorbed As $\left(\mathrm{mg} \mathrm{kg}^{-1}\right), C_{o}$ is initial As concentration $\left(\mathrm{mg} \mathrm{L}^{-1}\right), t$ is reaction time $(\mathrm{min}), k_{a}$ is sorption rate coefficient $\left(\mathrm{min}^{-1}\right)$, and $1 / m$ is constant. $R^{2}$ is determination coefficient and $\mathrm{SE}$ is standard error of estimate.
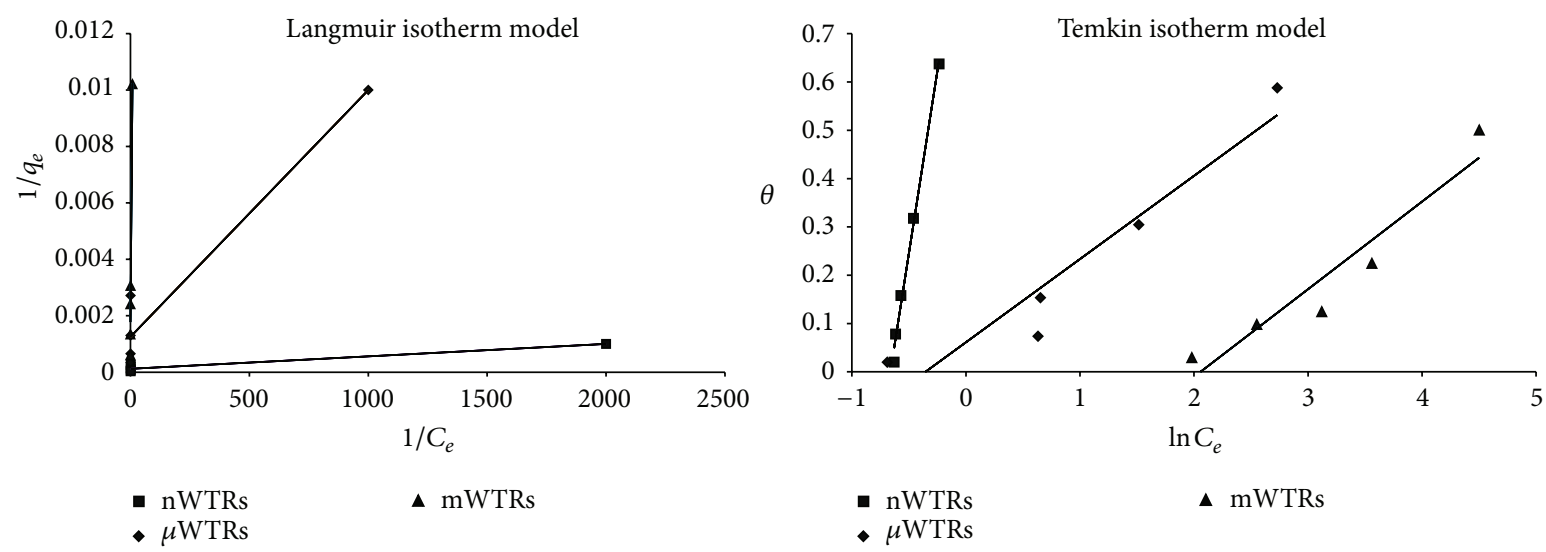

FIGURE 5: Arsenic sorption isotherm models for different particle sizes of WTR.

model assumed that the adsorption enthalpy $\Delta H$ decreases linearly with increasing surface coverage and adsorbentadsorbate interactions [21]. The results (Table 1) showed that the adsorption reactions of $\mathrm{As}(\mathrm{V})$ on mWTR, $\mu \mathrm{WTR}$, and nWTR are exothermic as $\Delta H$ values are negative for all WTRs studied.

\subsection{Selection of the Operating Conditions for the Adsorption Study}

3.4.1. Adsorbent Dose. The effect of adsorbent dose on As(V) adsorption by nWTR is shown in Figure 6. The isotherms indicate greater differences in As sorption capacities among different doses. Adsorption of As increases rapidly with increasing adsorbent dose of nWTR from 0.020 to $0.10 \mathrm{~g} / \mathrm{L}$. The isotherm of $0.10 \mathrm{~g} / \mathrm{L}$ dose showed nearly a vertical line and has been classified as $\mathrm{H}$-type isotherms suggesting a very strong metal-nWTR surface interaction [22]. The increase in As removal efficiency with increasing adsorbent dose could be attributed to more surface area available with increasing adsorbent dose. The adsorbent dose of $0.10 \mathrm{~g} / \mathrm{L}$ was used in the subsequent studies.

3.4.2. Effect of Solution $p H$. The effect of $\mathrm{pH}$ on $\mathrm{As}(\mathrm{V})$ adsorption by nanoscale WTR in the $\mathrm{pH}$ range of 3-11 is shown in Figure 7. It can be seen that As(V) adsorption by nWTR was highly $\mathrm{pH}$-dependent. The maximum efficiency of $\mathrm{As}(\mathrm{V})$ removal by $\mathrm{nWTR}$ was at $\mathrm{pH} 3(88 \%)$ and the least 
TABLE 2: Equilibrium model constants and standard error of estimate and determination coefficients for arsenic adsorption by the three different particles sizes of WTR.

\begin{tabular}{|c|c|c|c|c|}
\hline Models & Parameter & mWTR & $\mu \mathrm{WTR}$ & nWTR \\
\hline \multirow{4}{*}{$\begin{array}{l}\text { Freundlich } \\
q_{e}=K_{F} C_{e}^{1 / n}\end{array}$} & $K_{F}\left(\mathrm{~mL} \mathrm{~g}^{-1}\right)$ & 194.377 & 251.137 & $132.32 \times 10^{3}$ \\
\hline & $1 / n$ & 0.3759 & 1.0005 & 6.143 \\
\hline & $R^{2}$ & 0.91 & 0.93 & 0.98 \\
\hline & SE & 0.36 & 0.40 & 0.23 \\
\hline \multirow{4}{*}{$\begin{array}{l}\text { Langmuir } \\
q_{e}=q_{\max }\left(K_{L} C_{e} / 1+K_{L} C_{e}\right)\end{array}$} & $q_{\max }\left(\mu \mathrm{gg}^{-1}\right)$ & 3333 & 5000 & 50000 \\
\hline & $K_{L}\left(\mathrm{~L} \mathrm{mg}^{-1}\right)$ & 1.8 & 144.44 & 250 \\
\hline & $R^{2}$ & 0.95 & 0.95 & 0.95 \\
\hline & SE & 0.001 & 0.001 & 0.0001 \\
\hline \multirow{4}{*}{$\begin{array}{l}\text { Elovich } \\
q_{e} / q_{m}=K_{E} C_{e} \exp \left(-q_{e} / q_{m}\right)\end{array}$} & $q_{\max }\left(\mu \mathrm{gg}^{-1}\right)$ & 2000 & 3333 & 20000 \\
\hline & $K_{E}\left(\mathrm{~L} \mathrm{mg}^{-1}\right)$ & 0.044 & 0.146 & 0.432 \\
\hline & $R^{2}$ & 0.93 & 0.97 & 0.98 \\
\hline & SE & 0.10 & 0.08 & 0.06 \\
\hline \multirow{4}{*}{$\begin{array}{l}\text { Temkin } \\
\theta=R T / \Delta Q \ln K_{0} C_{e}\end{array}$} & $\Delta Q\left(\mathrm{~kJ} \mathrm{~mol}^{-1}\right)$ & 13.584 & 14.372 & 1.639 \\
\hline & $K_{0}\left(\mathrm{Lg}^{-1}\right)$ & 7.930 & 1.426 & 1.94 \\
\hline & $R^{2}$ & 0.91 & 0.91 & 0.99 \\
\hline & SE & 0.06 & 0.06 & 0.02 \\
\hline \multirow{4}{*}{$\begin{array}{l}\text { Fowler-Guggenheim (FG) } \\
K_{\mathrm{FG}} C_{e}=\theta / 1-\theta \exp (2 \theta w / R T)\end{array}$} & $W\left(\mathrm{~kJ} \mathrm{~mol}^{-1}\right)$ & 12.816 & 5.2309 & 3.9852 \\
\hline & $K_{\mathrm{FG}}\left(\mathrm{L} \mathrm{mg}^{-1}\right)$ & 1.6093 & 1.0899 & 1.0849 \\
\hline & $R^{2}$ & 0.97 & 0.96 & 0.97 \\
\hline & SE & 0.39 & 0.22 & 0.17 \\
\hline \multirow{4}{*}{$\begin{array}{l}\text { Kiselev } \\
k_{1} C_{e}=\theta /(1-\theta)\left(1+k_{n} \theta\right)\end{array}$} & $k_{1}\left(\mathrm{~L} \mathrm{mg}^{-1}\right)$ & 0.288 & 22.118 & 44.17 \\
\hline & $k_{n}$ & 5.537 & 5.776 & 5.48 \\
\hline & $R^{2}$ & 0.95 & 0.95 & 0.95 \\
\hline & SE & 0.996 & 119.55 & 225.03 \\
\hline \multirow{4}{*}{$\begin{array}{l}\text { Hill-de Boer } \\
K_{1} C_{e}=\theta /(1-\theta) \exp \left(\theta /(1-\theta)-K_{2} \theta / R T\right)\end{array}$} & $K_{1}\left(\mathrm{~L} \mathrm{mg}^{-1}\right)$ & 4.371 & 1.785 & 1.303 \\
\hline & $K_{2}\left(\mathrm{~kJ} \mathrm{~mol}^{-1}\right)$ & 54.22 & 14.841 & 4.037 \\
\hline & $R^{2}$ & 0.87 & 0.94 & 0.98 \\
\hline & SE & 1.74 & 0.38 & 0.07 \\
\hline
\end{tabular}

$q_{e}\left(\mathrm{mg} \mathrm{g}^{-1}\right)$ is $\mathrm{P}$ adsorbed per gram of adsorbent, $C_{e}\left(\mathrm{mg} \mathrm{L}^{-1}\right)$ is equilibrium $\mathrm{P}$ concentration in solution, $K_{F}$ is a constant related to adsorption capacity of the adsorbent $\left(\mathrm{L} \mathrm{mg}^{-1}\right), n$ is a constant, $q_{\max }\left(\mathrm{mg} \mathrm{g}^{-1}\right)$ is the maximum adsorption capacity of the adsorbent, $K_{L}\left(\mathrm{~L} \mathrm{mg}^{-1}\right)$ is Langmuir constant related to the free energy of adsorption, $\theta$ is fractional coverage, $R$ is the universal gas constant $\left(\mathrm{kJ} \mathrm{mol}^{-1} \mathrm{~K}^{-1}\right), T$ is the temperature $(\mathrm{K}), \Delta Q$ is $(-\Delta H)$ the variation of adsorption energy $\left(\mathrm{kJ} \mathrm{mol}^{-1}\right), K_{0}$ is Temkin constant $\left(\mathrm{L} \mathrm{mg}^{-1}\right), K_{\mathrm{FG}}$ is Fowler-Guggenheim constant $\left(\mathrm{L} \mathrm{mg}^{-1}\right), w$ is the interaction energy between adsorbed molecules $\left(\mathrm{kJ} \mathrm{mol}^{-1}\right), k_{1}$ is Kiselev constant $\left(\mathrm{L} \mathrm{mg}^{-1}\right), k_{n}$ is a constant of complex formation between adsorbed molecules, $K_{1}$ is Hill-de Boer constant $\left(\mathrm{L} \mathrm{mg}^{-1}\right)$, and $K_{2}$ $\left(\mathrm{kJ} \mathrm{mol}^{-1}\right)$ is a constant related to the interaction between adsorbed molecules. A positive $K_{2}$ means attraction between adsorbed species and a negative value means repulsion.

efficiency of As removal by nWTR was at $\mathrm{pH} 11$ (14.9\%). These results show clearly that As can be readily adsorbed by $\mathrm{nWTR}$ in an acidic $\mathrm{pH}$ range. Because $\mathrm{As}(\mathrm{V})$ species $\left(\mathrm{H}_{2} \mathrm{AsO}_{4}{ }^{-}, \mathrm{HAsO}_{4}{ }^{2-}\right.$, and $\left.\mathrm{AsO}_{4}{ }^{3-}\right)$ exist as negative anions at the investigated $\mathrm{pH}$ values (3-11) $[23,24]$, the low efficiency of $\mathrm{As}(\mathrm{V})$ removal at high $\mathrm{pH}$ values could be due to the increase in the coulomb repulsive force between the surface of nWTR nanoparticles and $\mathrm{As}(\mathrm{V})$ when the solution $\mathrm{pH}$ increases from 3 to 11 [25].

3.4.3. Initial As Concentration and Competing Ions. The effect of initial As $(\mathrm{V})$ concentration on the extent of adsorption by nWTR was investigated at As initial concentrations ranges $5-160 \mathrm{mg} / \mathrm{L}$ and the results are shown in Figure 8. When initial As $(\mathrm{V})$ concentrations were changed from 5 to $160 \mathrm{mg} / \mathrm{L}$ at room temperature, the amount sorbed per unit mass showed an increase with rise in initial $\mathrm{As}(\mathrm{V})$ concentrations. This is due to the increase in the mass driving force which allows more As $(\mathrm{V})$ molecules to pass from the solution to the adsorbent surface. At low As(V) initial concentration, the ratio of $A s(V)$ in solution to the available sorption sites is small and consequently the sorption is dependent of the initial concentration, but as the concentration of the As(V) increases, the competition for sorption sites becomes fierce [26].

The removal of (As) by nWTR was markedly affected by the presence of $\mathrm{Hg}$ and $\mathrm{Cr}$ (Figure 8). The efficiency of As removal considerably decreased from $99 \%$ to $16.7-18.3 \%$ due 


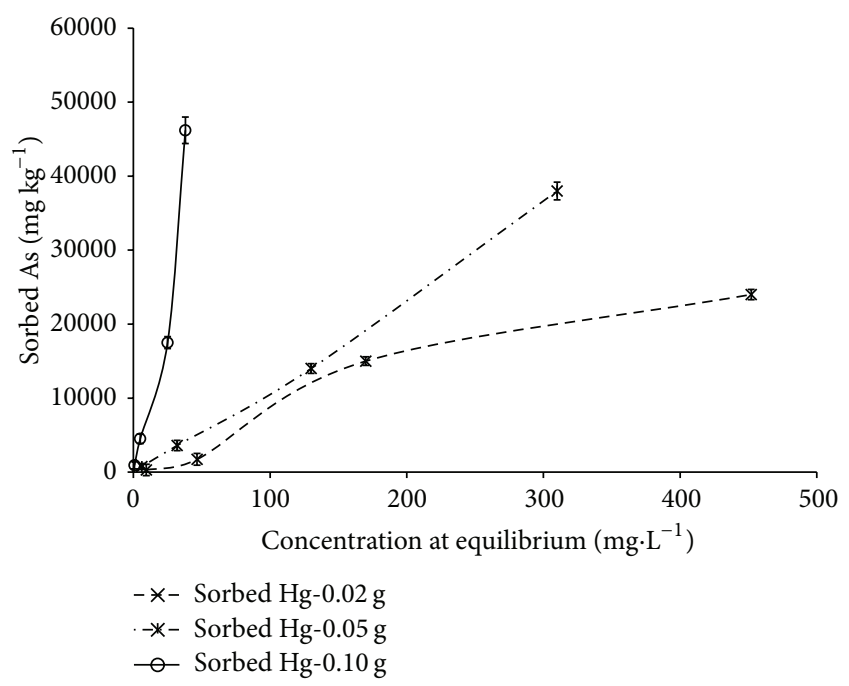

FIGURE 6: Effect of adsorbent dose on As sorbed by nWTR. Adsorption of As increases rapidly with increasing adsorbent dose of nWTR from 0.020 to $0.10 \mathrm{~g}$.

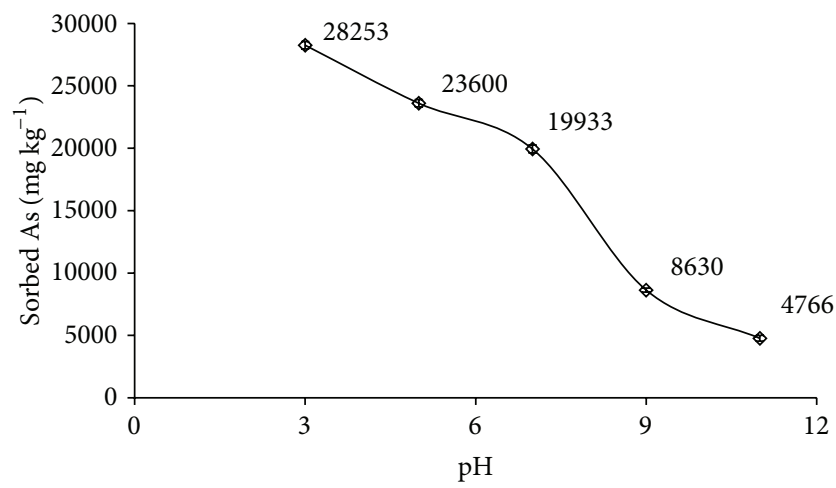

FIgURE 7: Effect of $\mathrm{pH}$ on $\mathrm{As}(\mathrm{V})$ adsorption by nWTR. The figure clearly shows that $\mathrm{As}(\mathrm{V})$ adsorption by nWTR was highly $\mathrm{pH}$ dependent.

to the competitive effect of $\mathrm{Hg}$ and $\mathrm{Cr}$ for the adsorption sites available to As. Similar adverse effect on the adsorption of As by mixed magnetite-maghemite nanoparticles through competitive adsorption mechanism was reported [27].

\subsection{Fractionation of the As-Saturated nWTR and As Mobility.} The SEM-EDX and XRD analyses confirmed that the three sorbents studied (nWTR, $\mu \mathrm{WTR}$, and mWTR) contained two elements ( $\mathrm{Fe}$ and $\mathrm{Al}$ ) that have a strong affinity for As (Figures 1 and 2). Therefore, to evaluate the potential mobility of As sorbed onto nWTR relative to $\mathrm{mWTR}$ and $\mu \mathrm{WTR}$, the fractionation scheme of Tessier et al. [28] was performed on the As-saturated sorbents. According to the scheme, the labile metals are extracted as five fractions: exchangeable, carbonates, oxides, organic matter, and residual fraction. The metals associated with the residual (RS) fraction are less mobile than metals associated with the nonresidual (NORS)

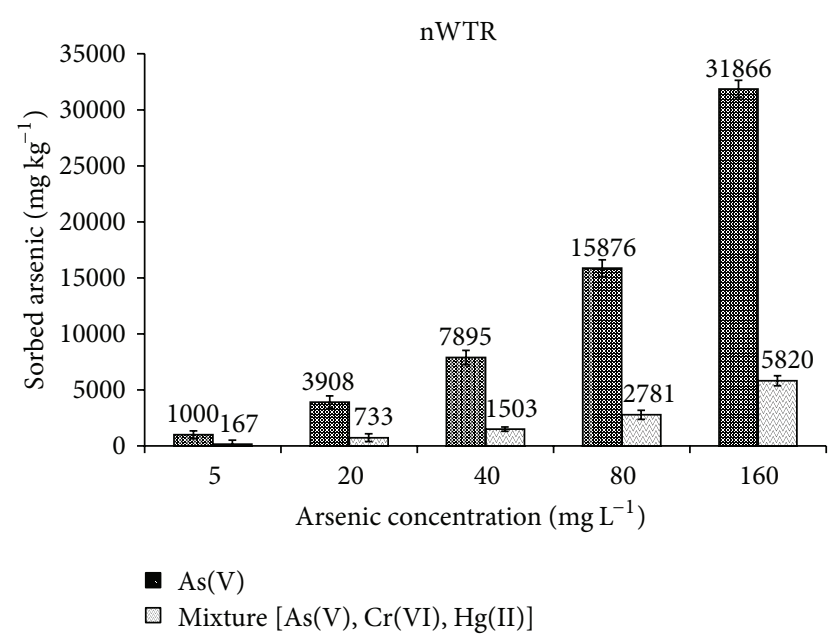

FIGURE 8: Arsenic(V) adsorption in the presence of two competing ions. Notice that the removal of (As) by nWTR was markedly affected by the presence of $\mathrm{Hg}(\mathrm{II})$ and $\mathrm{Cr}(\mathrm{VI})$.

fraction (sum of all fractions except the residual fraction). The As fractionation results (Figure 9) show that As adsorbed on mWTR was mostly associated with the more mobile nonresidual fraction (67\%) whereas $80 \%$ of As on nWTR was associated with the residual fraction (RS), the less mobile fraction. The association of much greater percentage of As in the residual fraction of nWTR indicates the higher capability of nWTR to immobilize As than bulk WTR (mWTR). These observations support the hypothesis that the smaller size and the higher surface area of WTR nanoparticles greatly enhance its sorptive characteristics and stability.

3.6. Fourier Transmission Infrared Spectroscopy (FTIR). The FTIR spectroscopic analysis was performed with FTIR spectrophotometer Model 4400 (Shimadzu Corporation, Japan) to investigate the adsorption mechanism of $\mathrm{As}(\mathrm{V})$ onto nWTR. Solid adsorbent was mixed with $\mathrm{KBr}$ in $1: 10$ ratio and pressed under 10 ton pressure into pellet and the infrared spectra were measured. The FTIR spectra of nWTR before and after As adsorption are demonstrated in Figure 10. The FTIR spectrum of WTR nanoparticles before As adsorption shows (1) $\mathrm{HOH}$ stretching $\left(3427 \mathrm{~cm}^{-1}\right)$ and bending $\left(1631 \mathrm{~cm}^{-1}\right)$ vibrations of $\mathrm{H}_{2} \mathrm{O}$ and (2) bending vibrations of hydroxyl groups on metal oxides $(\mathrm{Al} \mathrm{OH})$ at $1046 \mathrm{~cm}^{-1}$ [29]. After As adsorption, the band at $3416 \mathrm{~cm}^{-1}(\mathrm{O}-\mathrm{H}$ bending vibration) and the four small peaks located between 3416 and $4012 \mathrm{~cm}^{-1}$ (attributed to the dangling $\mathrm{O}-\mathrm{H}$ bonds on the surface of the $\mathrm{H}_{2} \mathrm{O}$ layer in nWTR) completely disappeared (Figure 10(a)). The decay of aforementioned peaks ascertained that the surface hydroxyl group on the surface of nWTR took part in the reaction with As.

Shifts in the peaks at 1626 and $1448 \mathrm{~cm}^{-1}$ on the surface of nWTR to higher wave numbers 1637 and $1462 \mathrm{~cm}^{-1}$ were noticed after As adsorption suggesting molecular interactions between $\mathrm{As}(\mathrm{V})$ and nWTR [30, 31]. However, due to the fact that stronger bonds usually vibrate faster than weaker bonds $[32,33]$, peaks at 1091 and $545 \mathrm{~cm}^{-1}(\mathrm{O}-\mathrm{Al}-\mathrm{O}$ stretching 


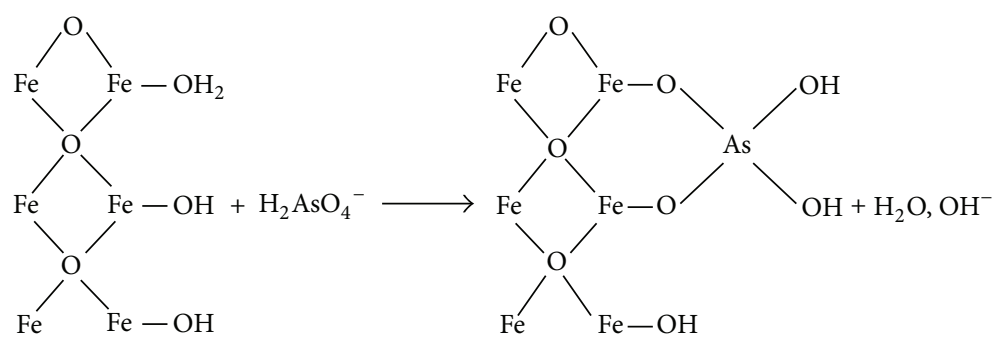

SCHEME 1

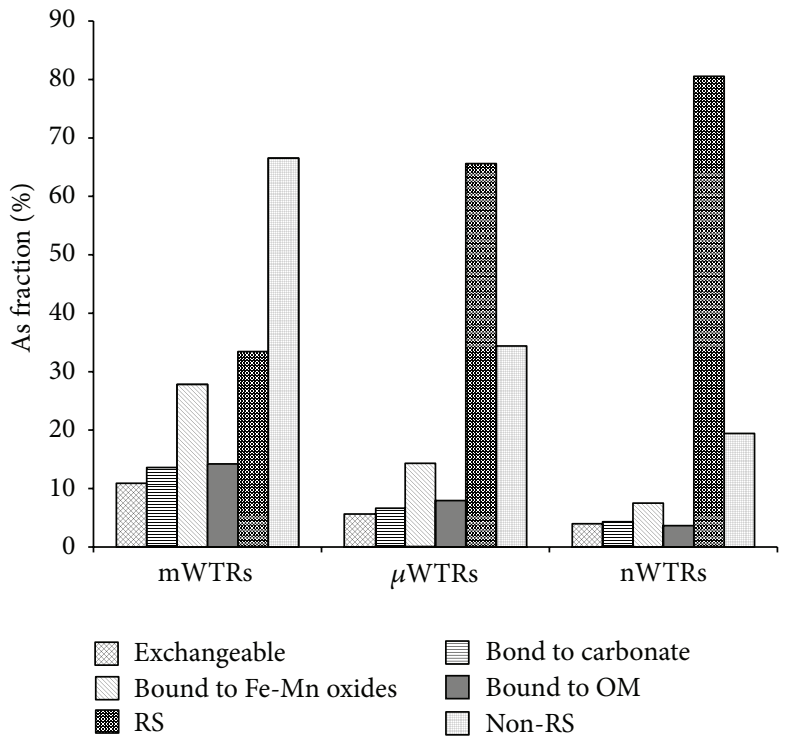

FIGURE 9: Fractionation of adsorbed As(V) on different particle sizes of WTR. Notice that As adsorbed on nWTR was mostly associated with the less mobile fraction (residual fraction, RS) which indicate the high capability of nWTR to immobilize As.

vibrations) on the surface of nWTR were shifted to lower wave numbers 1033 and $534 \mathrm{~cm}^{-1}$, respectively, after arsenate adsorption.

Based on the aforementioned discussion on $\mathrm{As}(\mathrm{V})$ adsorption by WTR nanoparticles, the following mechanisms of $\mathrm{As}(\mathrm{V})$ adsorption are proposed.

(1) On Iron Sites. Arsenate anion is strongly bound to two adjacent structural $\mathrm{Fe}^{3+}$ cations through surface hydroxyl groups and form a bidentate surface complex. The surface complexation modeling study of Fukushi and Sverjensky [34] predicted that the dominant arsenate species on the surface of hematite will be a fully deprotonated bridging bidentate complex at lower $\mathrm{pH}$ values and higher surface coverage than the mononuclear species as shown in Scheme 1.

(2) On Aluminum Sites. Adsorption of arsenate ions onto aluminum hydroxides sites can be explained by the formation of inner-sphere complexes between arsenate and the singly coordinated hydroxyl groups as represented by the following equations:

$$
\begin{gathered}
\equiv \mathrm{Al}-\mathrm{OH}+\mathrm{H}_{2} \mathrm{AsO}_{4}{ }^{-} \longleftrightarrow \equiv \mathrm{AlH}_{2} \mathrm{AsO}_{4}{ }^{-}+\mathrm{OH}^{-} \\
2 \equiv \mathrm{Al}-\mathrm{OH}+\mathrm{H}_{2} \mathrm{AsO}_{4}{ }^{-} \longleftrightarrow(\equiv \mathrm{Al})_{2} \mathrm{HAsO}_{4}+\mathrm{H}_{2} \mathrm{O}+\mathrm{OH}^{-}
\end{gathered}
$$

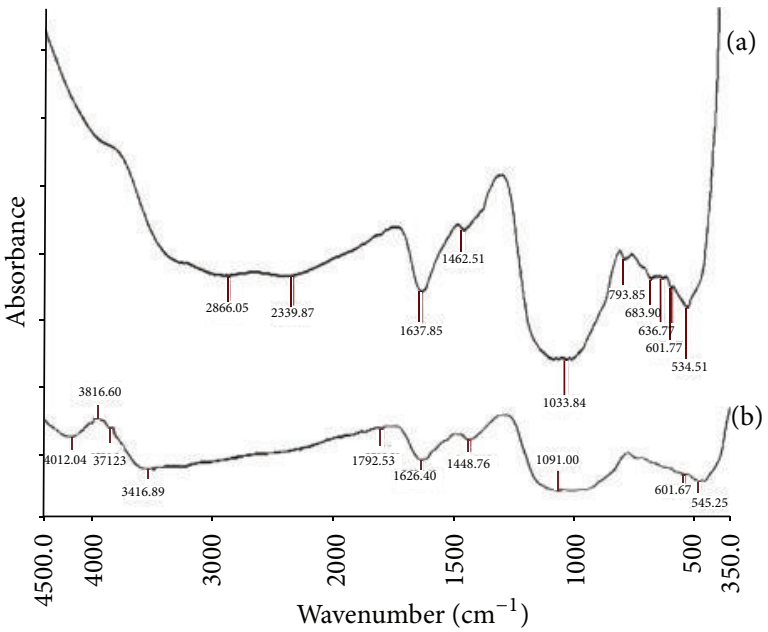

FIGURE 10: Fourier transmission infrared (FTIR) spectrum of nWTR (a) after $\mathrm{As}(\mathrm{V})$ adsorption and (b) before $\mathrm{As}(\mathrm{V})$ adsorption.

Because arsenate is not strongly bound to $\mathrm{Al}(\mathrm{OH})_{3}$ as to Fe oxides, it is suggested that formation of monodentate complex or outer-sphere complex could be possible bonding mechanisms on $\mathrm{Al}$ sites. The recent X-ray scattering evidence supports the presence of inner-sphere and outer-sphere $\mathrm{As}(\mathrm{V})$ on similar aluminol sites in corundum [35].

3.7. Desorption Behavior. To determine the stability of As removed by nWTR, desorption behaviors of As-loaded nWTR at various As concentrations were studied. Portions of high purity water $(10.0 \mathrm{~mL})$ were added to $0.1 \mathrm{~g}$ of arsenicloaded nWTR and shaken. After $24 \mathrm{~h}$, the solution was filtered and the filtrate was acidified and analyzed for As. The percentages of As desorbed after four consecutive cycles are shown in Figure 11. The amounts of As released increased from 0.49 to $1.73 \%$ as the As concentrations increased from 5 to $500 \mathrm{mg} / \mathrm{L}$ (at $\mathrm{pH} \mathrm{7.0)}$ ). It is clear that the As adsorbed on nWTR was not significantly altered as less than $2 \%$ of adsorbed As was released at the highest As concentration load after 4 consecutive desorption cycles. These results suggest the stability of As-nWTR surface complexes.

\section{Conclusion}

A low cost adsorbent, water treatment residual nanoparticles, has proven to be effective in As $(\mathrm{V})$ removal from the aqueous solution. Kinetics data reveal that $89 \%$ of $\mathrm{As}(\mathrm{V})$ was adsorbed 


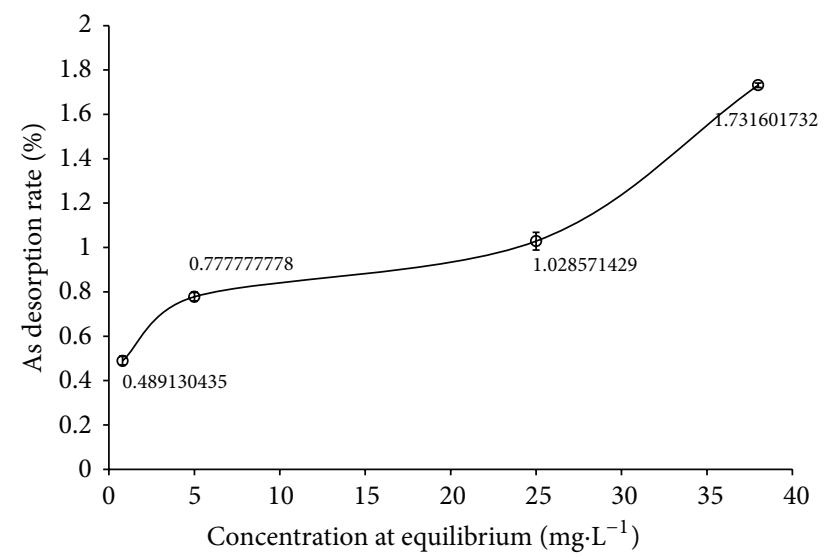

FIGURE 11: Desorption of As(V) from nWTR loaded with different As concentrations. Notice the stability of As adsorbed on nWTR as less than $2 \%$ of adsorbed As was released after 4 consecutive desorption cycles.

by nWTR within the first $15 \mathrm{~min}$ and slowly preceded to $100 \%$ sorption by the end of the $24 \mathrm{~h}$ period. The equilibrium data fitted well to the Langmuir and Temkin models and the maximum adsorption capacity $\left(q_{\max }\right)$ of WTR nanoparticles was 16 times higher than $q_{\max }$ of Bulk WTR. The As(V) removal by nWTR was strongly dependent on $\mathrm{pH}$ and the formation of bidentate and monodentate surface complexes could be possible bonding mechanisms for As(V) sorption on Fe and $\mathrm{Al}$ sites, respectively. The high capability of nWTR to remove $A s(V)$ from aqueous media and the stability of As-nWTR surface complexes suggest the great potential of nWTR as economic and effective sorbent for removal of As from contaminated natural water and wastewater.

\section{Conflict of Interests}

The authors declare that there is no conflict of interests regarding the publication of this paper.

\section{Acknowledgment}

The authors gratefully acknowledge the financial support from the Egyptian Science and Technology Development Fund (STDF 4977-2013).

\section{References}

[1] D. Mohan and C. U. Pittman Jr., "Arsenic removal from water/wastewater using adsorbents-a critical review," Journal of Hazardous Materials, vol. 142, no. 1-2, pp. 1-53, 2007.

[2] T. S. Y. Choong, T. G. Chuah, Y. Robia, F. L. G. Koay, and I. Azni, "Arsenic toxicity, health hazards and removal techniques from water: an overview," Desalination, vol. 217, no. 1-3, pp. 139-166, 2007.

[3] K. Košutić, L. Furač, L. Sipos, and B. Kunst, "Removal of arsenic and pesticides from drinking water by nanofiltration membranes," Separation and Purification Technology, vol. 42, no. 2, pp. 137-144, 2005.
[4] Y.-H. Xu, T. Nakajima, and A. Ohki, "Adsorption and removal of arsenic(V) from drinking water by aluminum-loaded Shirasuzeolite," Journal of Hazardous Materials, vol. 92, no. 3, pp. 275287, 2002.

[5] Y. Zhang, M. Yang, and X. Huang, "Arsenic(V) removal with a Ce(IV)-doped iron oxide adsorbent," Chemosphere, vol. 51, no. 9, pp. 945-952, 2003.

[6] US Environmental Protection Agency (USEPA), Arsenic Treatment Technologies for Soil, Waste, and Water, EPA-542-R-02004, Office of Solid Waste and Emergency Response, 2002.

[7] N. Savage and M. S. Diallo, "Nanomaterials and water purification: opportunities and challenges," Journal of Nanoparticle Research, vol. 7, no. 4-5, pp. 331-342, 2005.

[8] R. P. Schwarzenbach, B. I. Escher, K. Fenner et al., "The challenge of micropollutants in aquatic systems," Science, vol. 313, no. 5790, pp. 1072-1077, 2006.

[9] J. A. Ippolito, K. A. Barbarick, D. M. Heil, J. P. Chandler, and E. F. Redente, "Phosphorus retention mechanisms of a water treatment residual," Journal of Environmental Quality, vol. 32, no. 5, pp. 1857-1864, 2003.

[10] D. Sarkar, K. C. Makris, V. Vandanapu, and R. Datta, "Arsenic immobilization in soils amended with drinking-water treatment residuals," Environmental Pollution, vol. 146, no. 2, pp. 414-419, 2007.

[11] E. A. Elkhatib, A. M. Mahdy, and M. M. ElManeah, "Effects of drinking water treatment residuals on nickel retention in soils: a macroscopic and thermodynamic study," Journal of Soils and Sediments, vol. 13, no. 1, pp. 94-105, 2013.

[12] E. A. Elkhatib and M. L. Moharem, "Immobilization of copper, lead, and nickel in two arid soils amended with biosolids: effect of drinking water treatment residuals," Journal of Soils and Sediments, vol. 15, no. 9, pp. 1937-1946, 2015.

[13] E. A. Elkhatib, A. M. Mahdy, and K. A. Salama, "Green synthesis of water treatment residual nanoparticles using precision milling," Environmental Chemistry Letters, vol. 13, pp. 333-339, 2015.

[14] A. G. Caporale, P. Punamiya, M. Pigna, A. Violante, and D. Sarkar, "Effect of particle size of drinking-water treatment residuals on the sorption of arsenic in the presence of competing ions," Journal of Hazardous Materials, vol. 260, pp. 644-651, 2013.

[15] E. A. Elkhatib, A. M. Mahdy, F. K. Sherif, and K. A. Salama, "Water treatment residual nanoparticles: a novel sorbent for enhanced phosphorus removal from aqueous medium," Current Nanoscience, vol. 11, no. 5, pp. 655-668, 2015.

[16] F.-S. Zhang and H. Itoh, "Iron oxide-loaded slag for arsenic removal from aqueous system," Chemosphere, vol. 60, no. 3, pp. 319-325, 2005.

[17] K. C. Makris, D. Sarkar, and R. Datta, "Evaluating a drinkingwater waste by-product as a novel sorbent for arsenic," Chemosphere, vol. 64, no. 5, pp. 730-741, 2006.

[18] E. A. Elkhatib, O. L. Bennett, and R. J. Wright, "Kinetics of arsenite sorption in soils," Soil Science Society of America Journal, vol. 48, no. 4, pp. 758-762, 1984.

[19] L. Zeng, "Arsenic adsorption from aqueous solutions on an Fe(III)-Si binary oxide adsorbent," Water Quality Research Journal of Canada, vol. 39, no. 3, pp. 267-275, 2004.

[20] T. A. Kurniawan and W.-H. Lo, "Removal of refractory compounds from stabilized landfill leachate using an integrated $\mathrm{H}_{2} \mathrm{O}_{2}$ oxidation and granular activated carbon (GAC) adsorption treatment," Water Research, vol. 43, no. 16, pp. 4079-4091, 2009. 
[21] K. Y. Foo and B. H. Hameed, "Insights into the modeling of adsorption isotherm systems," Chemical Engineering Journal, vol. 156, no. 1, pp. 2-10, 2010.

[22] C. H. Giles, T. H. MacEwan, N. S. Nakhwa, and D. Smith, "Studies in sorption. Part XI. A system of classification of solution adsorption isotherms, and its use in diagnosis on adsorption mechanisms and in measurement of specific surface areas of solids," Journal of the Chemical Society, vol. 111, pp. 3973-3993, 1960.

[23] D. Mohan and C. U. Pittman Jr., "Arsenic removal from water/wastewater using adsorbents-a critical review," Journal of Hazardous Materials, vol. 142, no. 1-2, pp. 1-53, 2007.

[24] B. A. Manning, M. L. Hunt, C. Amrhein, and J. A. Yarmoff, "Arsenic(III) and arsenic(V) reactions with zerovalent iron corrosion products," Environmental Science and Technology, vol. 36, no. 24, pp. 5455-5461, 2002.

[25] C. Wang, H. Luo, Z. Zhang, Y. Wu, J. Zhang, and S. Chen, "Removal of As(III) and As(V) from aqueous solutions using nanoscale zero valent iron-reduced graphite oxide modified composites," Journal of Hazardous Materials, vol. 268, pp. 124131, 2014.

[26] R. Saravanane, T. Sundararajan, and S. S. Reddy, "Efficiency of chemically modified low cost adsorbents for the removal of heavy metals from waste water: a comparative study," Indian Journal of Environmental Health, vol. 44, no. 2, pp. 78-87, 2002.

[27] S. R. Chowdhury and E. K. Yanful, "Arsenic and chromium removal by mixed magnetite-maghemite nanoparticles and the effect of phosphate on removal," Journal of Environmental Management, vol. 91, no. 11, pp. 2238-2247, 2010.

[28] A. Tessier, P. G. C. Campbell, and M. Blsson, "Sequential extraction procedure for the speciation of particulate trace metals," Analytical Chemistry, vol. 51, no. 7, pp. 844-851, 1979.

[29] Y. Zhang, M. Yang, X.-M. Dou, H. He, and D.-S. Wang, "Arsenate adsorption on an Fe-Ce bimetal oxide adsorbent: role of surface properties," Environmental Science and Technology, vol. 39, no. 18, pp. 7246-7253, 2005.

[30] V. M. Bermudez, "Effect of humidity on the interaction of dimethyl methylphosphonate (DMMP) vapor with $\mathrm{SiO}_{2}$ and $\mathrm{Al}_{2} \mathrm{O}_{3}$ surfaces, studied using infrared attenuated total reflection spectroscopy," Langmuir, vol. 26, no. 23, pp. 18144-18154, 2010.

[31] P. Tarte, "Infra-red spectra of inorganic aluminates and characteristic vibrational frequencies of $\mathrm{AlO}_{4}$ tetrahedra and $\mathrm{AlO}_{6}$ octahedra," Spectrochimica Acta Part A: Molecular Spectroscopy, vol. 23, no. 7, pp. 2127-2143, 1967.

[32] D. A Skoog, F. J. Holler, and T. A. Nieman, Principles of Instrumental Analysis, Harcourt Brace and Company, Orland, Calif, USA, 5th edition, 1998.

[33] K. B. Payne and T. M. Abdel-Fattah, "Adsorption of arsenate and arsenite by iron-treated activated carbon and zeolites: effects of $\mathrm{pH}$, temperature, and ionic strength," Journal of Environmental Science and Health-Part A: Toxic/Hazardous Substances and Environmental Engineering, vol. 40, no. 4, pp. 723-749, 2005.

[34] K. Fukushi and D. A. Sverjensky, "A predictive model (ETLM) for arsenate adsorption and surface speciation on oxides consistent with spectroscopic and theoretical molecular evidence," Geochimica et Cosmochimica Acta, vol. 71, no. 15, pp. 3717-3745, 2007.

[35] J. G. Catalano, C. Park, P. Fenter, and Z. Zhang, "Simultaneous inner- and outer-sphere arsenate adsorption on corundum and hematite," Geochimica et Cosmochimica Acta, vol. 72, no. 8, pp. 1986-2004, 2008. 

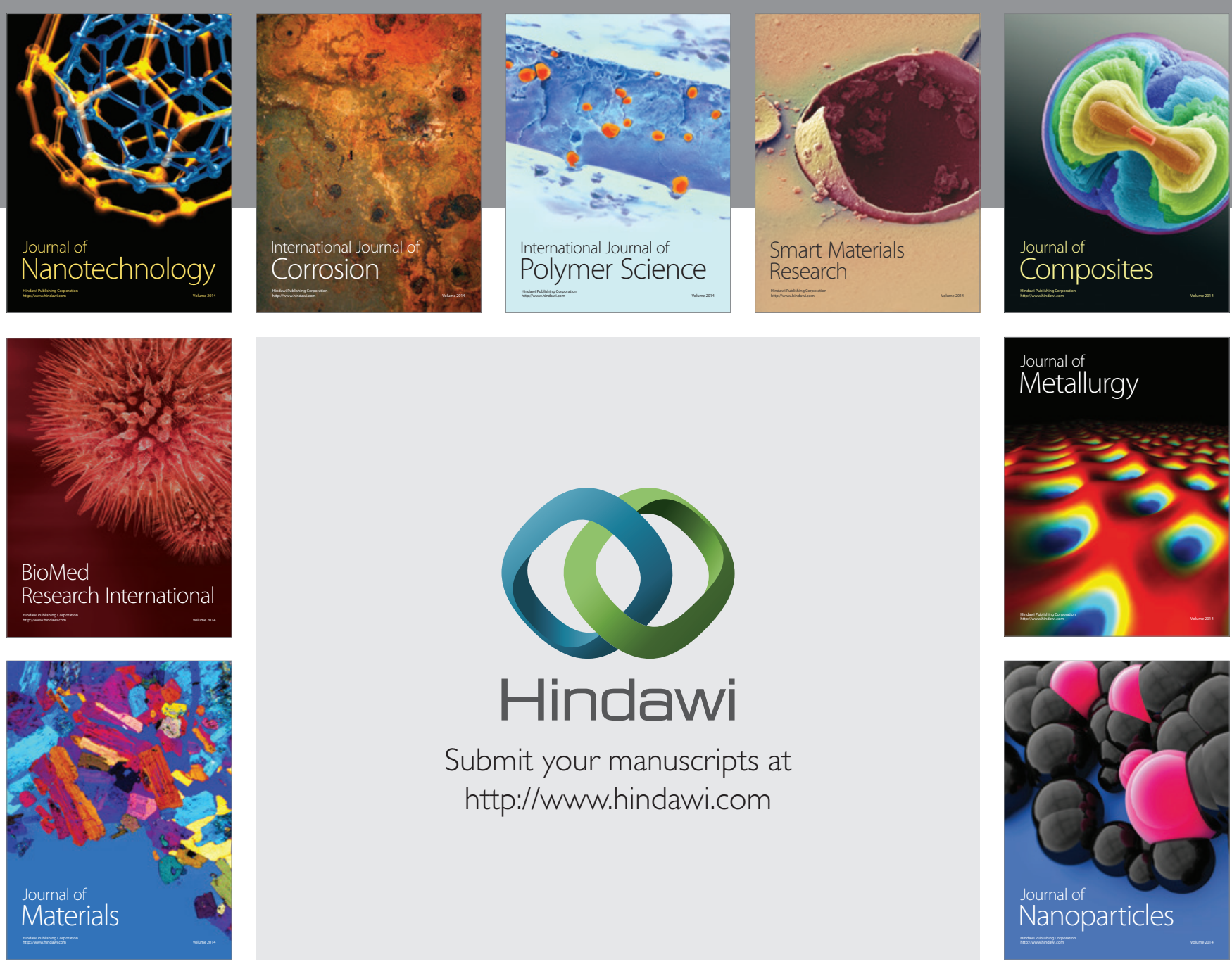

Submit your manuscripts at http://www.hindawi.com
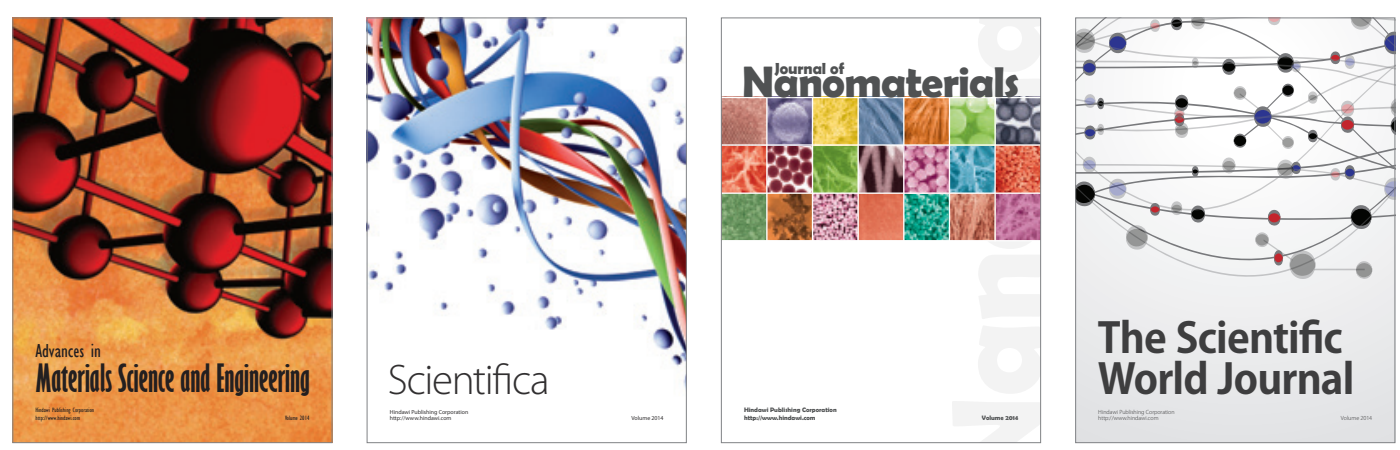

\section{The Scientific World Journal}
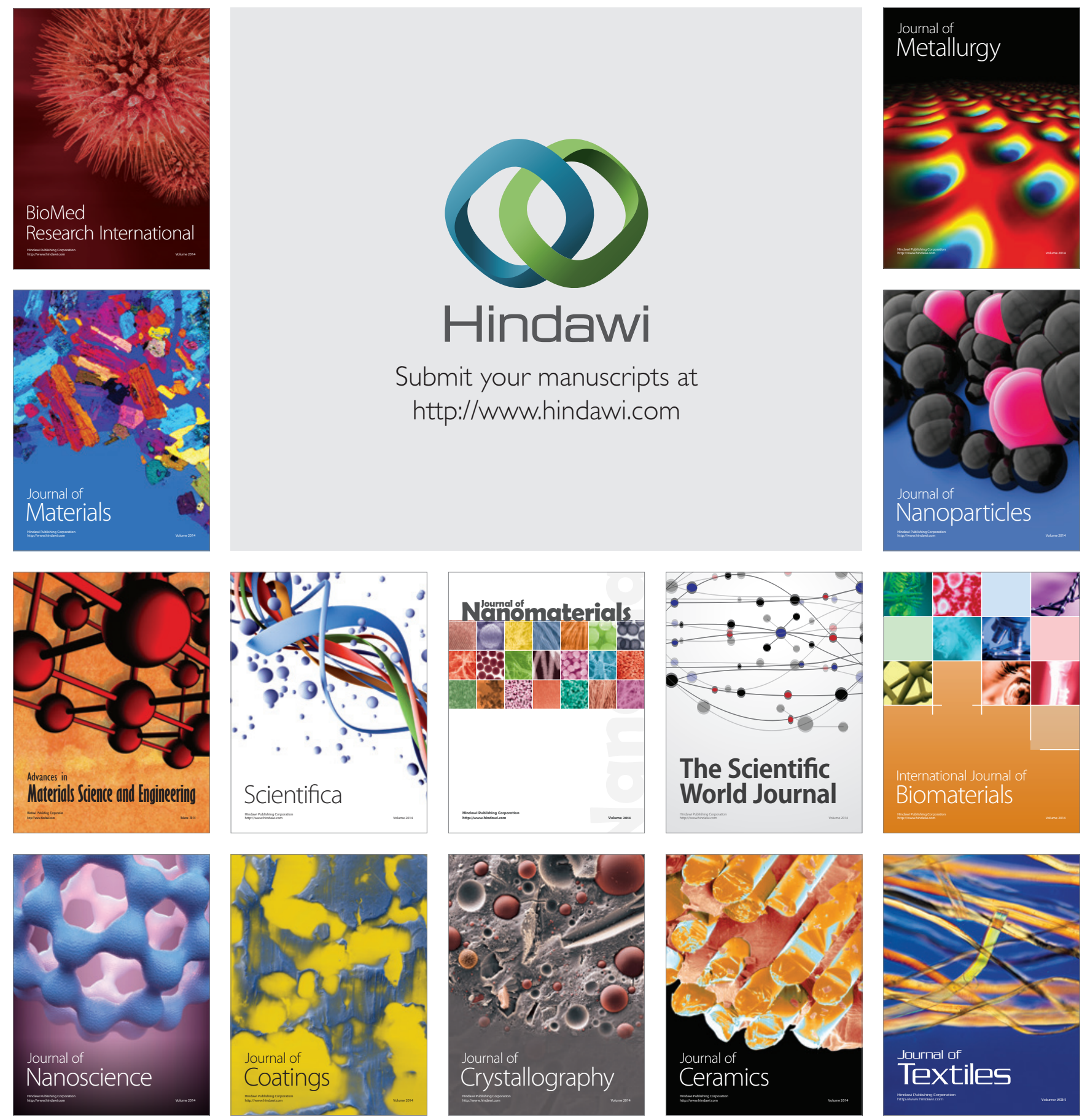